spectral blue and violet. A colour triangle of roughly uniform colour discrimination can be constructed. but it is not entirely satisfactory for all purposes.

The wide spread of Professor Wright's influence was illustrated by four papers dealing with the present-day scene. The first dealt with the physiology of colour processing by the brain in human vision, and the second with the related problems of congenital and acquired colour vision defects. The third paper was concerned with developments in spectrophotometry and colorimetry up to the present time. The advent of new light sources, various types of energy detector, and the influence of computer technology and software science have together transformed the precision and speed with which colour measurements may be made.

The final paper in this group dealt with what from several points of view might be called the delicate subject of painting and fabric conservation. Professor Wright again has made a notable contribution by designing a reflectance spectrophotometer to study the long-term changes in colour caused by chemical oxidation and physical fading, a topic of great concern to art galleries and building conservators the world over.

The last, but by no means the least, contribution was made by Mike Pointer (Kodak) who spoke about getting colour science right in the future. $\mathrm{He}$ gave a wide-ranging survey, looking at instruments, theory, applications and education. Whilst perhaps there is declining support for, and interest in, fundamental research in colour, there is a growing industrial interest, with rapid changes in the technology of photography, television, paint and printing. There is certainly no shortage of problems to tackle!

On a more personal note the day was rounded off by the presentation of many tributes and gifts to David Wright, and to Mrs Wright, the cutting and sharing of a splendid birthday cake, and the lighting of a single giant candle. a reminder not only of the birthday, but of the candela as an SI fundamental standard. A very happy and instructive occasion.

Kenneth Spring

\section{Breakthrough in colour LCD}

Japan Display 86 SID/Institute of Television Engineers of Japan, 30 September-2 October 1986, Tokyo

The Display Research Conference, originally a (biannual) American affair organised by the Society for Information Display (SID), became international in 1981 and now rotates annually between the USA, Europe and Japan. This year it was organised jointly by the Institute of Television Engineers of Japan and SID, with 14 other academic societies supporting the event - which shows the interest the Japanese have in the subject.

The name 'Display Research Conference' implies that matters of a more fundamental nature are presented and discussed, as compared with the annual SID symposium and exhibition (see Phys. Technol. 198617232 ). Also in Tokyo the range of subjects was classical: devices based on the modulation of positions and/or densities of electrons, plasma, physical states in fluids and in solids, mechanical and thermal devices. Coverage of this vast range in one conference must be at the expense of depth, even when presented in several parallel sessions. However, particularly in the areas of cathode-ray tubes (CRT) and of active-matrixaddressed liquid-crystal displays ( $L C D$ ), we heard and saw some exciting and convincingly good developments.

Stealing the show was Hosiden with two contributions in the poster sessions: one a 5 in diagonal active-matrix full-colour LCD for TV operation, the other a $130 \times 130 \mathrm{~mm}^{2}$ active-matrix colour data display with resolution of $5 \mathrm{line} / \mathrm{mm}$ ! Both have high contrast and good colour saturation under normal room lighting conditions. The trend in quality upgrading of CRTS continues: better yokes and gun optics, improved shadow-mask suspension, leading to smaller spots and larger, flat, direct-view display area. Another eyecatcher was the University of Illinois $512 \times 512$ independent-sustain-andaddress plasma display panel, operating at $50 \mathrm{frame} / \mathrm{s}$, using half the normal number of address drivers.

Counting papers and posters alike, the emphasis was clearly on liquid-crystal devices (direct and active addressing, materials) where there were 57 contributions; other areas covered were: cathoderay tubes and vacuum fluorescent displays ( 21 contributions); electroluminescent displays (16); gas discharge panels or plasma displays (8); and other. e.g. electrochromic devices, also (8). Further contributions were on hardcopy and printing (12); display systems (8); human factors and image processing (12). A special session was devoted to automotive displays since the new technologies are slowly being incorporated into the dashboards of new cars. For this application the programmability of the electro-optical display device is a valuable asset as it allows switching between the common data of car engine, system and speed, navigation instructions, roadworks and expected delays and so on, under control of the onboard computer.

One paper suggested the use of the head-up 
display as now installed in aircraft, where the data to be displayed are projected on the windscreen but collimated at infinity so that the range accommodation of the eyes need not switch between near (the instrument) and far (traffic situation).

New (and something of a solution looking for a problem) was an electrochromic mirror with electrically controlled reflectance $\left(160 \mathrm{~cm}^{2}\right)$, and the use of electrochromism in combination with liquid crystals to produce a laser addressed light valve. Finally it must be mentioned that more and more mathematical models are being developed which serve to predict the visual characteristics of display devices and to optimise the device parameters.

The next Display Research Conference will be held on 15-17 September this year at the IEE building, London. With so much research going on in the field, this conference is bound to be very interesting; and being so close it should be a must for every designer and user of systems which rely on proper display operation.

Professor D Bosman University of Twente. The Netherlands

\section{PVDF applications}

PVDF: a versatile electrically active polymer Fulmer Research Institute, 28 October 1986, Fulmer, Slough

In the early 1970 s, films of polyvinylidene fluoride ( $P V D F$ or $\mathrm{PVF}_{2}$ ) were marketed in Japan. These had piezo- and pyroelectric properties which could be used in transducer devices. Progress in these applications has been slow. However, in the past few years a group of UK research organisations have been extending their activities based on material supplied by the Yarsley subsidiary of the Fulmer Research Institute. More recently a club of users has been formed and the meeting at Fulmer was organised to show the existing and potential applications of PVDF. About 60 people actively participated in the programme sessions.

The topics ranged from the production of the material in several forms to its actual uses with theoretical consideration of limitations in performance. Both well established devices (such as the Fulmer series of polymer transducers) and more individual applications (e.g. uses as a detector for monitoring movement of babies in cots, given in a presentation by G M Kennard of Vickers Medical) were covered.

The basic paper was given by A P Verrall (Yarsley
Technical Centre) who discussed the fabrication of the films and how the PVDF properties depended on extrusion and orientation parameters as well as the poling treatment (molecular reorientation under an electric field). The advantages of the cable over sheet form for some applications were demonstrated by K Sudworth (Raychem). A comparison of properties of material in this form was carried out by two approaches - analytical and finite-element methods (J R Dunn and B V Smith, University of Birmingham). Theoretical and practical results were in reasonable agreement. The application of PVDF in radiation pyrometry (A $\mathrm{R}$ Piercy, Brighton

Polytechnic) gave enhanced responsivity when used in the current rather than the voltage mode relative to $\mathrm{LiTaO}_{3}$ and $\operatorname{PzT}\left(\mu \mathrm{V} \mathrm{m}^{2} \mathrm{~W}^{-1}: 28700,1438\right.$ and 1000 respectively).

R J Redding (Design Automation) concluded from his detailed analysis of several systems that the future for PVDF instrumentation lies with the progress of continuous-wave ultrasonic measurement and similar sensing using nonintrusive wave motion. Work at the NPL (D Bacon) has allowed the performance of hydrophones to be determined and compared with theoretical behaviour. Further developments based on a beam calibration system have permitted rapid and reliable measurement of acoustic fields. Commercial instruments were now available. In a separate paper practical transducers were considered in further detail by P D Wilson (Fulmer).

The following general impressions were gained from the meeting. In parallel with increased activity in sensors the interest in PVDF has grown. The disadvantages relative to ceramics, e.g. lower efficiency, are steadily being overcome by utilising the favourable characteristics, e.g. availability of larger areas and relatively lower cost. Future developments in enhancing the piezo- and pyroelectric properties both in PVDF and in other electronic polymers are also progressing well. Ultrasonic applications continue to dominate the scene but extensions in other fields are likely as the beneficial properties are more fully exploited by electronic techniques. Defence uses have provided a technology pull to the developments which now are increasingly being applied in the civil field.

Finally, the club shows the benefits in the materials field of having links among suppliers, research institutions, manufacturers of devices and a financial organisation such as Cogent.

Copies of the abstracts of the papers and more information about the club can be obtained from D N Adamson, Fulmer Research Laboratories Ltd, Stoke Poges, Slough SL2 4QD, Berks, England (tel. 02816 2181)

\section{Bovey Materials \& Design}

